\title{
Light-Dependent Induction of Early-Response Gene Expression by Calphostin-C
}

\author{
Shinobu Gamou and Nobuyoshi Shimizu* \\ Department of Molecular Biology, Keio University School of Medicine, 35 Shinanomachi, Shinjuku-ku, \\ Tokyo, 160, Japan
}

Key words: protein kinase $\mathrm{C} /$ gene expression/calphostin-C/EGF receptor

\begin{abstract}
$A B S T R A C T$. Calphostin-C is a compound possessing the ability to inhibit protein kinase C (PKC) by oxidative modification in vitro and to enhance the epidermal growth factor (EGF) receptor phosphorylation in vivo in a light-dependent manner. Here, we found that calphostin-C induced $\mathrm{c}$-fos and c-jun mRNA accumulation in the lung adenocarcinoma cell line A549 in a light-dependent manner. Nuclear run-on assay revealed that this mRNA accumulation took place at the transcription level. However, unlike in vitro, calphostin-C did not inhibit cytosolic PKC activity in vivo, and the gene expression induced by calphostin-C was inhibited by another PKC inhibitor, staurosporine. Thus, it was suggested that calphostin-C activates cytosolic PKC-dependent signaling pathway to the induction of "early-response gene" expression in a light-dependent manner.
\end{abstract}

Protein kinase $C$ (PKC) plays important roles in the signaling cascade from the epidermal growth factor (EGF) receptor to the nucleus. EGF activates tyrosine kinase of the EGF receptor which leads to autophosphorylation on carboxyl-terminal tyrosine residues, phosphorylation of phospholipase $\mathrm{C}_{\gamma}$, and subsequent hydrolysis of phosphatidylinositol (23). Another rapid response following EGF binding to its receptor is the increased expression of a set of "early-response genes" (19). Two of these are the proto-oncogenes c-fos and cjun. c-fos and c-jun gene products are nuclear proteins and form a heterodimer or a homodimer complex with AP-1 activity (17), which activates transcription of certain genes through interaction with their promoter region $(15,18)$. Regulation of c-fos and c-jun gene expression involves protein kinase(s) including PKC. Thus, the use of specific kinase inhibitors may provide additional insight to dissect the role of PKC in signal transduction pathways to the nucleus.

Among the PKC inhibitors, calphostin-C, a secondary metabolite of the fungus Cladosporium cladosporioides (21), possesses several unique features. First, calphostin-C interacts with the diacylglycerol binding site of PKC (16), while other inhibitors such as staurosporine interact with the catalytic site (21). Since the catalytic site is more conserved throughout protein kinase families and the diacylglycerol binding site is unique to $\mathrm{PKC}$, the inhibition by calphostin- $\mathrm{C}$ is assumed to be more specific for PKC than other kinase inhibitors. A

\footnotetext{
* To whom correspondence should be addressed.

Abbreviations used: PKC, protein kinase C; EGF, epidermal growth factor; DMEM, Dulbecco's modified Eagle's medium; TPA, 12-O-tetradecanoylphorbol 13-acetate.
}

unique feature of calphostin-C is that the inhibition of PKC in vitro is light-dependent (4). The light-dependency results from photo-dynamic activation of perylenequinone structure of calphostin- $\mathrm{C}$ to generate active oxygen, followed by the oxidative modification of PKC (10).

In addition to the inhibition of $\mathrm{PKC}$, another unique feature of calphostin-C is the enhancement of the EGF receptor phosphorylation on serine and threonine residues in a light-dependent manner but rather PKC-independent oxidative reaction (8). To further characterize the biological consequences of this unique receptor phosphorylation, we examined the effect of calphostin$\mathrm{C}$ on the expression of early-response genes c-fos and c$j u n$ and found that calphostin-C stimulated the expression of these genes in a light-dependent manner. This finding suggests that calphostin-C in vivo acts as a potent activator of a signal transduction pathway to earlyresponse gene expression.

\section{MATERIALS AND METHODS}

Cell culture. Human lung adenocarcinoma cell line A549 (12) was kindly provided by Dr. M. Akiyama (Radiation Effects Research Institute, Hiroshima, Japan). A549 cells were grown in Dulbecco's modified Eagle's medium (DMEM) supplemented with fetal calf serum (10\%) and kanamycin $(100 \mu \mathrm{g} / \mathrm{ml})$ at $5 \% \mathrm{CO}_{2}$ and $100 \%$ humidity. The cells were treated with calphostin-C (1 $\mu \mathrm{M}$, Kyowa Hakko, Tokyo, Japan) under the illumination of a $15 \mathrm{~W}$ fluorescent lamp in a $\mathrm{CO}_{2}$ incubator (4). In some experiments, cells were treated with staurosporine ( $1 \mu \mathrm{M}$, Kyowa Hakko), EGF $(50 \mathrm{ng} / \mathrm{ml}$, ultra pure grade, Toyobo Co., Osaka, Japan) and 12-O-tetra- 
decanoylphorbol 13-acetate (TPA) $(10 \mathrm{ng} / \mathrm{ml})$.

EGF receptor phosphorylation. EGF receptor phosphorylation and immunoprecipitation analysis was carried out as described previously $(6,7,13)$. A549 cells were labeled with $\left[{ }^{32} \mathrm{P}\right]$ orthophosphate (3.7 MBq/ml, carrier-free, ICN Biomedicals, Irvine, CA, USA) in DMEM containing one-tenth concentration of phosphate and supplemented with dialyzed fetal calf serum for $4 \mathrm{~h}$. Cells were then treated with calphostin-C and lysed in Triton X-100 lysis buffer (1\% Triton X-100, $1 \mathrm{mM}$ EDTA, $150 \mathrm{mM} \mathrm{NaCl}, 50 \mathrm{mM}$ Tris-HCl, pH 7.4, $0.1 \mathrm{mM}$ phenylmethylsulfonyl fluoride). The lysates were clarified by centrifugation and the supernatants were incubated with antihuman EGF receptor antibody (B4G7) (2) bound to protein A-Sepharose (Pharmacia-LKB Biotechnology, Uppsala, Sweden) for $4 \mathrm{~h}$. The receptor-antibody complex on the Sepharose was washed extensively and analyzed by electrophoresis on a SDS-polyacrylamide gel (7\%). Autoradiography and quantitation of radioactivity was carried out using a BAS2000 Bio-imaging analyzer (Fuji Photo Film, Tokyo, Japan).

Northern blot analysis. Northern blot analysis was carried out as described previously (9). In brief, cellular RNAs were extracted by the LiCl-urea method (1). Total RNAs $(20 \mu \mathrm{g})$ were fractionated by electrophoresis on a formalin-agarose gel $(0.9 \%)$ and transferred to a nylon membrane (GeneScreen Plus, NEN Research Products, Boston, MA, USA). cDNA probes were labeled with $\left[\alpha-{ }^{32} \mathrm{P}\right] \mathrm{dCTP}$ (NEN Research Products) by the random primer method (5). Autoradiography and quantitative analysis was carried out as described above. c-fos cDNA pSPT-fos (22) and c-jun cDNA pHJ (3) were pro- vided by the Japanese Cancer Research Resources Bank, Tokyo, Japan, and by Dr. D. Bohmann, University of California, Berkeley, CA, USA, respectively.

Nuclear run-on transcription analysis. Nuclear run-on transcription analysis was carried out as described (11) with slight modification. Cells (approximately $1 \times 10^{7}$ ) were treated with calphostin-C and/or EGF and collected in phosphatebuffered saline. Cells were incubated in the extraction buffer $\left(10 \mathrm{mM} \mathrm{NaCl}, 3 \mathrm{mM} \mathrm{MgCl}_{2}, 0.5 \%\right.$ Triton X-100, $10 \mathrm{mM}$ Tris$\mathrm{HCl}, \mathrm{pH}$ 7.4) for $5 \mathrm{~min}$ at $4^{\circ} \mathrm{C}$ and centrifuged for $5 \mathrm{~min}$ at $1,000 \mathrm{rpm}$ at $4^{\circ} \mathrm{C}$. The nuclear pellet was washed with the extraction buffer and suspended in the storage solution $(5 \mathrm{mM}$ $\mathrm{MgCl}_{2}, 1 \mathrm{mM}$ EDTA, $40 \%$ glycerol, $10 \mathrm{mM}$ Tris- $\mathrm{HCl}, \mathrm{pH}$ 8.0 ). The nuclei were then mixed with equal volume of the transcription buffer $\left(5 \mathrm{mM} \mathrm{MgCl}_{2}, 300 \mathrm{mM} \mathrm{KCl}, 0.25 \mathrm{mM}\right.$ ATP, $0.25 \mathrm{mM}$ GTP, $0.25 \mathrm{mM}$ UTP, $3.7 \mathrm{MBq}\left[\alpha{ }^{32} \mathrm{P}\right] \mathrm{CTP}$, $10 \mathrm{mM}$ Tris- $\mathrm{HCl}, \mathrm{pH} 8.0$ ) and incubated for $30 \mathrm{~min}$ at $30^{\circ} \mathrm{C}$. The nuclear transcript was extracted by the LiCl-urea method as described above. The plasmid DNAs $(10 \mu \mathrm{g})$ containing cfos and c-jun cDNA and the vector DNA (pUC18) were immobilized on a nylon membrane. The hybridization with labeled nuclear transcript, membrane wash and autoradiography was carried out as in the Northern blot analysis.

$P K C$ activity. PKC activity in the cytosolic fraction was measured as described previously (12). A549 cells were treated with calphostin-C, staurosporine or TPA and lysed in SEAT buffer $(0.25 \mathrm{M}$ sucrose, $1 \mathrm{mM}$ EDTA, $10 \mathrm{mM}$ acetic acid, 10 $\mathrm{mM}$ triethanolamine, $\mathrm{pH}$ 7.4) by pipetting with a Gilson P1000 Pipetman. After centrifugation at 1,000 rpm for $5 \mathrm{~min}$

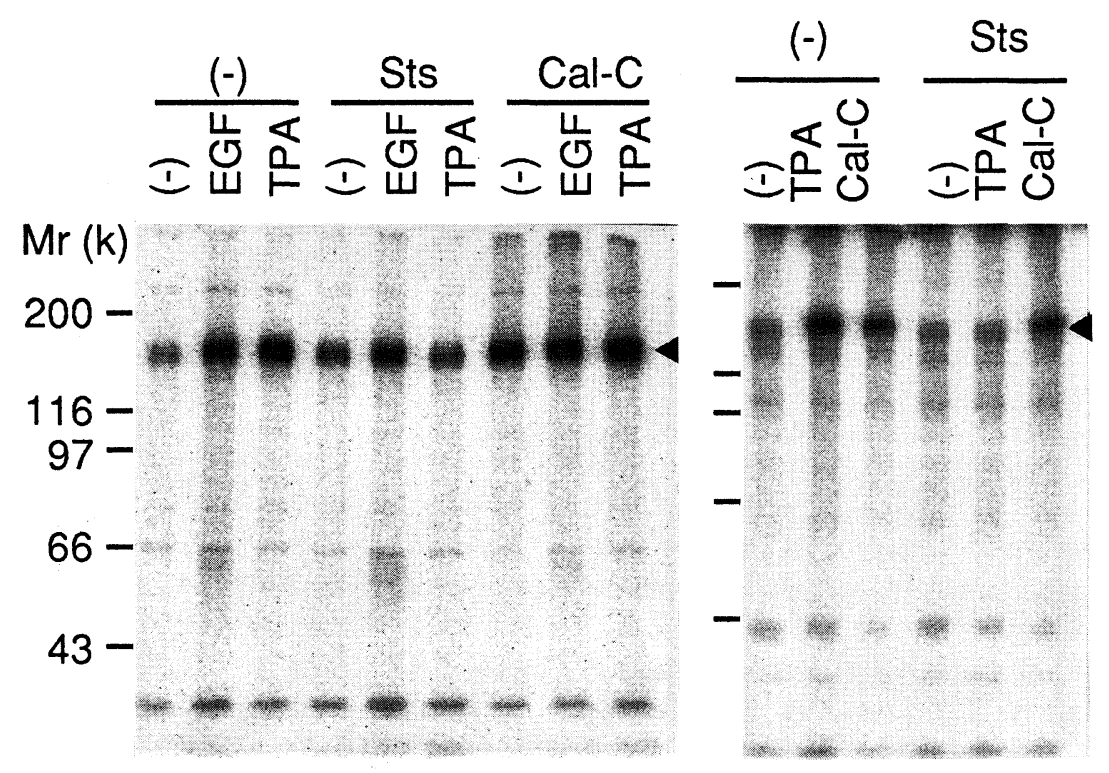

Fig. 1. EGF receptor phosphorylation induced by calphostin-C.

A549 cells were labeled with [ $\left.{ }^{32} \mathrm{P}\right]$ orthophosphate for $4 \mathrm{hr}$ and treated with staurosporine (Sts) or calphostin-C (Cal-C) for $30 \mathrm{~min}$ under light. Cells were further treated with EGF, TPA or calphostin-C for 15 min under light, and lysed for the immunoprecipitation using anti-human EGF receptor monoclonal antibody B4G7. The immunoprecipitates were analyzed by SDS-polyacrylamide gel (7\%) electrophoresis, followed by autoradiography in a BAS2000 Bio-imaging analyzer. 
to remove nuclei and cell debris, the lysates were centrifuged at $100,000 \mathrm{rpm}$ for $15 \mathrm{~min}$ in a Beckman TLA100.2 rotor and the supernatants were used as the cytosolic fraction. PKC activity in the cytosolic fraction was assayed using histone as a substrate. For in vitro assay, PKC was partially purified from the cytosolic fraction of A549 cells by DE52-cellulose chromatography. After calphostin-C/light treatment in the presence or absence of $\mathrm{Ca}^{+}(1 \mathrm{mM})$ for $15 \mathrm{~min}$ on ice, PKC activity was assayed.

\section{RESULTS}

Calphostin-C/light induces phosphorylation of the EGF receptor. We previously demonstrated that calphostin-C enhances EGF receptor phosphorylation in the EGF receptor-hyperproducing cell line NA (8). Here, we examined whether calphostin-C enhances EGF receptor phosphorylation in the human lung adenocarcinoma cell line A549 which possesses the normal number of EGF receptor and high PKC activity (12).

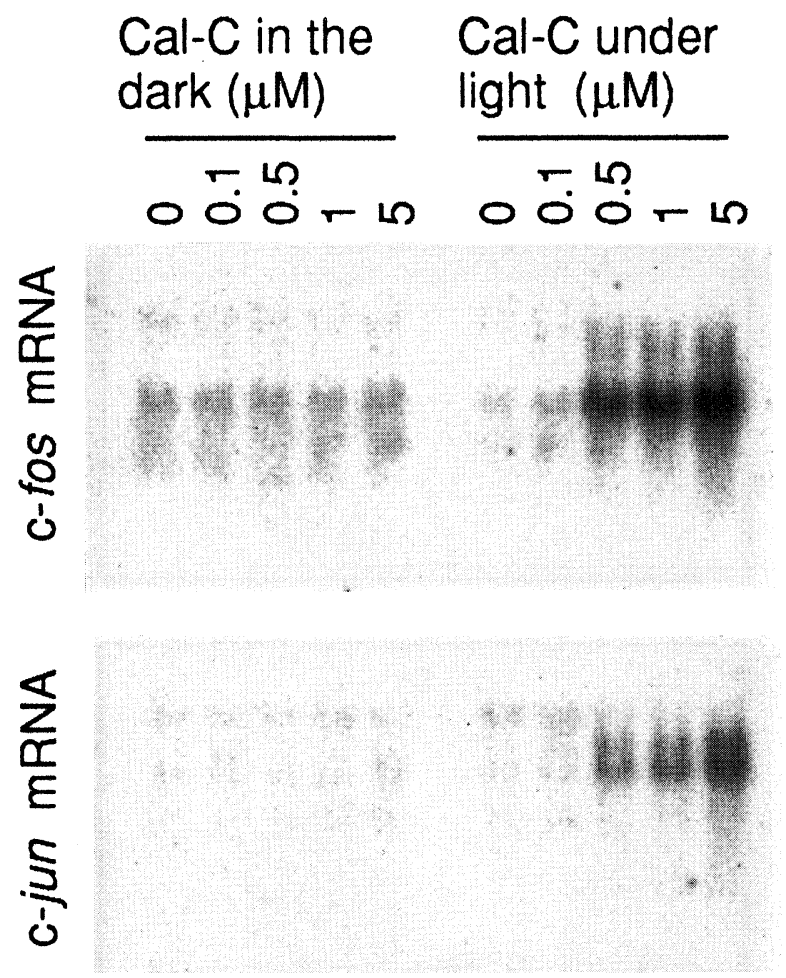

Fig. 2. Dose- and light-dependent induction of c-fos and c-jun mRNA by calphostin-C.

A549 cells were treated with various concentrations of calphostin-C (Cal-C) either in the dark or under light for 60 min. RNAs were extracted and Northern blot hybridization analysis was carried out using c-fos and c-jun cDNA probes, which were labeled with $\left[{ }^{32} \mathrm{P}\right]$ dCTP by the random primer method. The autoradiography and quantitative analysis were carried out using a BAS2000 Bio-imaging analyzer.

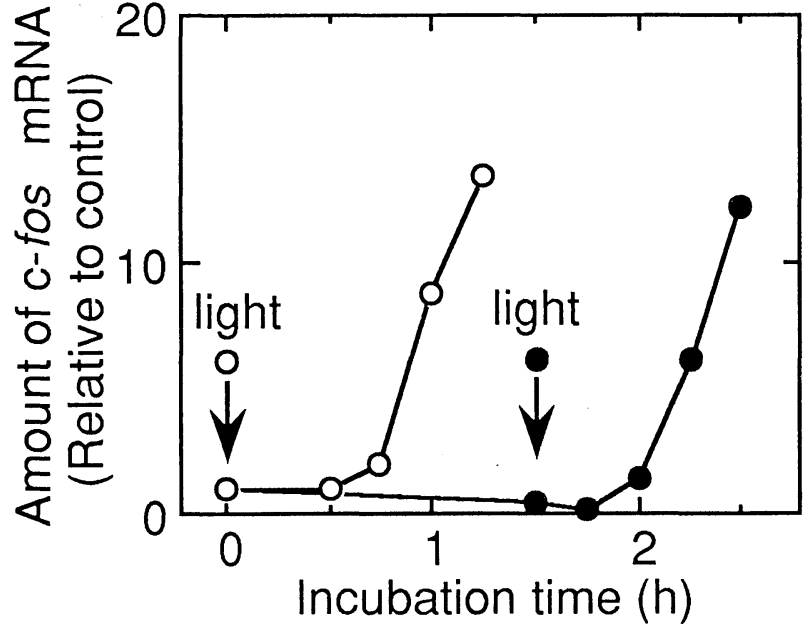

Fig. 3. Light dependent induction of c-fos mRNA.

A549 cells were treated with calphostin-C under light for the indicated times. RNAs were extracted and Northern blot analysis was carried out using a c-fos cDNA probe as described in Fig. 2.

$\bigcirc$, treated under light; $\bullet, 90 \mathrm{~min}$ in the dark and then under light.

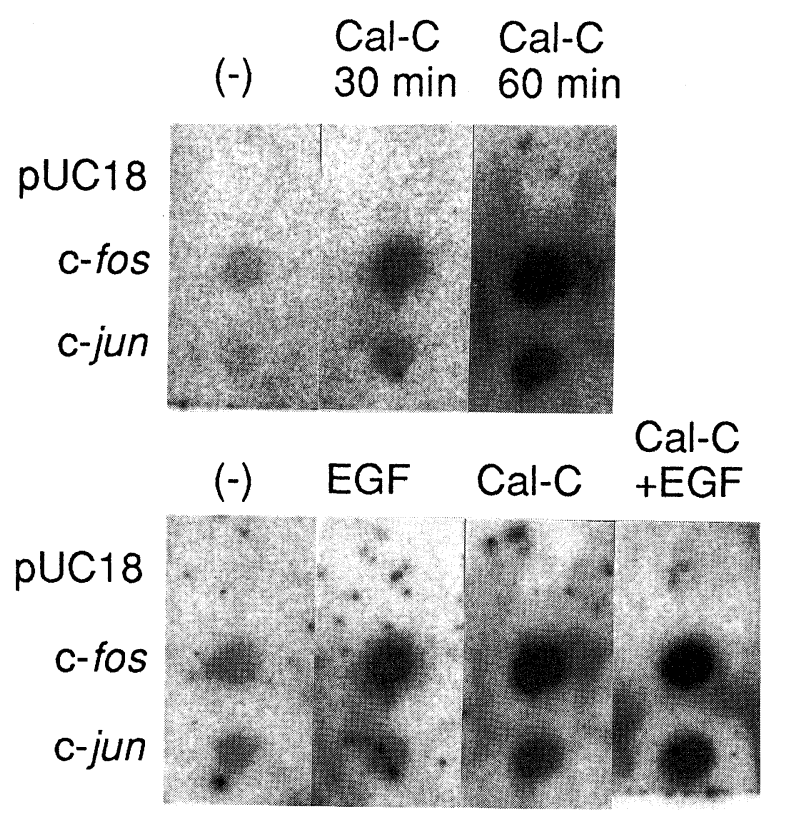

Fig. 4. Nuclear run-on analysis of calphostin-C induction of c-fos and c-jun mRNA.

A549 cells were treated with calphostin-C for $30 \mathrm{~min}$ or $60 \mathrm{~min}$ (top), or with calphostin-C and/or EGF for $30 \mathrm{~min}$ (bottom). The cells were then lysed to isolate the nuclei. The isolated nuclei were labeled with $\left[\alpha-{ }^{32} \mathrm{P}\right] \mathrm{CTP}$, and nuclear transcripts were extracted by the $\mathrm{LiCl} /$ urea method. The plasmid DNA containing c-fos and c-jun cDNA and the pUC18 vector plasmid DNA were immobilized on a nylon membrane with a dot-blot apparatus. Hybridization of labeled nuclear transcripts with DNAs on the membrane, washing and autoradiography were carried out as Northern blot analysis described in Fig. 2. 
Calphostin-C under light enhanced receptor phosphorylation 2- to 3-fold regardless of the presence of EGF or TPA (Fig. 1). However, another PKC inhibitor, staurosporine completely inhibited TPA-induced receptor phosphorylation, but not EGF-induced receptor phosphorylation, suggesting staurosporine specifically inhibits PKC. EGF receptor phosphorylation was on serine and threonine residues and maximal at $30 \mathrm{~min}$ after calphostin-C treatment under light (data not shown). Furthermore, EGF receptor phosphorylation induced by calphostin-C was not inhibited by staurosporine (Fig. 1), suggesting that PKC is not involved in the EGF receptor phosphorylation process.

Calphostin- $C$ under light induces $c$-fos and c-jun $m R N A$ accumulation. To further examine the biological consequences of this unique receptor phosphorylation, we examined the effect of calphostin-C on c-fos and c-jun gene expression in A549 cells. Calphostin-C treatment under light induced c-fos and c-jun mRNA accumulation, while calphostin-C in the dark did not (Fig. 2). Calphostin-C induction of c-fos and c-jun mRNA was dose-dependent and the magnitude of induction was similar to that of the induction by EGF. When cells were incubated with calphostin-C under light, c-fos mRNA accumulation was detected within $45 \mathrm{~min}$, but in the dark no c-fos mRNA accumulation was observed even after $90 \mathrm{~min}$. Subsequent incubation under light induced c-fos mRNA accumulation (Fig. 3). In contrast, EGF- and TPA-induced c-fos mRNA accu- mulation was maximum at $30 \mathrm{~min}$ regardless of light (data not shown). Thus, this induction of early-response gene expression involves a light-dependent intracellular activation of calphostin-C.

Calphostin-C/light induces the transcriptional activation of c-fos and c-jun gene. To examine whether cfos and c-jun mRNA accumulation by calphostin-C /light involves a transcriptional activation, a nuclear run-on transcription assay was carried out. As shown in Fig. 4, a time-dependent increase of c-fos and c-jun transcripts was observed in the nuclei from calphostin-C /light treated cells. Also, an increase of c-fos and c-jun transcripts was observed in the nuclei of cells treated with both calphostin-C and EGF. These results suggested that the accumulation of early-response gene transcripts took place at the transcriptional level.

Calphostin-C/light induction of gene expression involves PKC. As with the previous report (10), calphostin-C/light in vitro inhibited partially purified PKC in the presence of $\mathrm{Ca}^{+}$(Fig. 5A). To determine whether cytosolic PKC is involved in the calphostin-C /light induction of early-response gene in vivo, cells were treated with either calphostin-C, staurosporine or TPA and then PKC activity in the cytosolic fraction was measured using histone as a substrate. When cells were treated with staurosporine for $30 \mathrm{~min}, \mathrm{PKC}$ activity in the cytosolic fraction was markedly reduced to approximately $20 \%$ of control (Fig. 5B). However, PKC activity was reduced only slightly when cells were

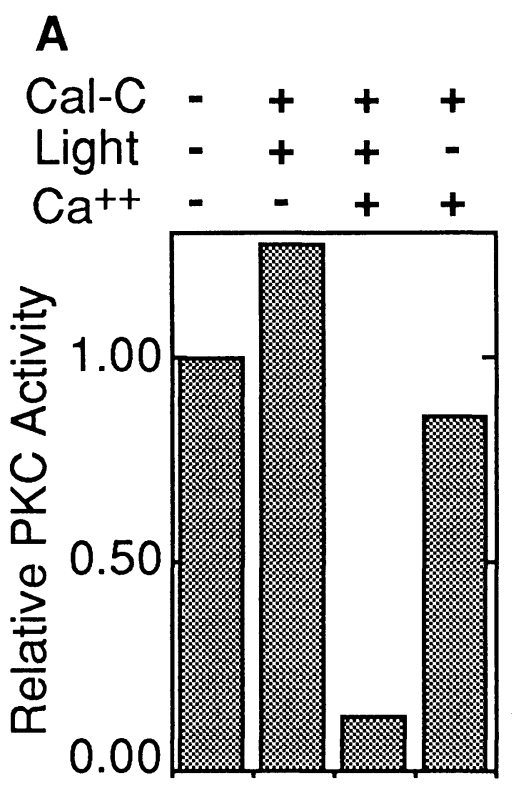

B

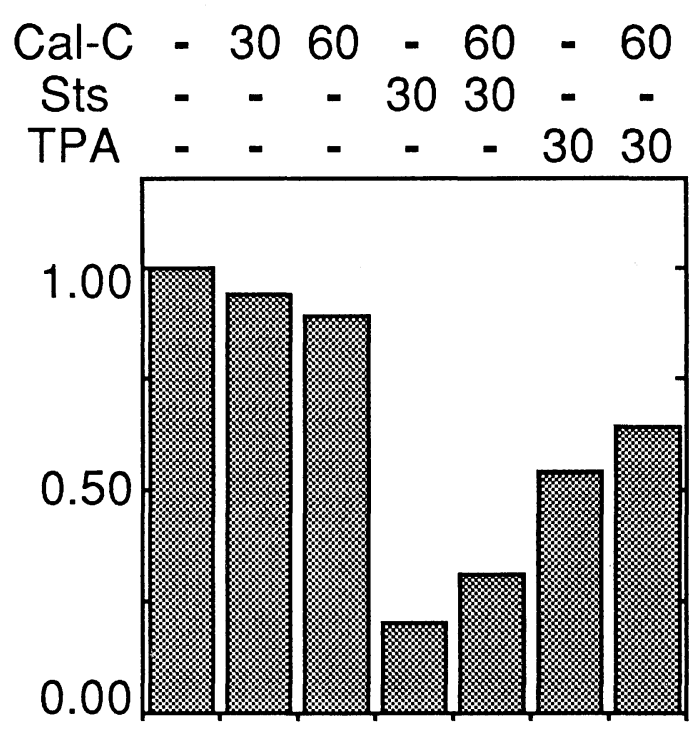

Fig. 5. PKC activity in cytosolic fraction.

A. Partially purified PKC from A549 cells was incubated with calphostin-C in the presence or absence of $\mathrm{CaCl}_{2}(1 \mathrm{mM})$ under light on ice for 15 min and then added into reaction mixture. PKC activity was measured using histone as a substrate at $30^{\circ} \mathrm{C}$ for 15 min. B. A549 cells were treated with calphostin-C (Cal-C) under light, staurosporine (Sts) and TPA and then lysed in SEAT buffer. PKC activity in the cytosolic fraction was measured. Each experiment consisted of triplicate samples. An average of three independent experiments was shown. 


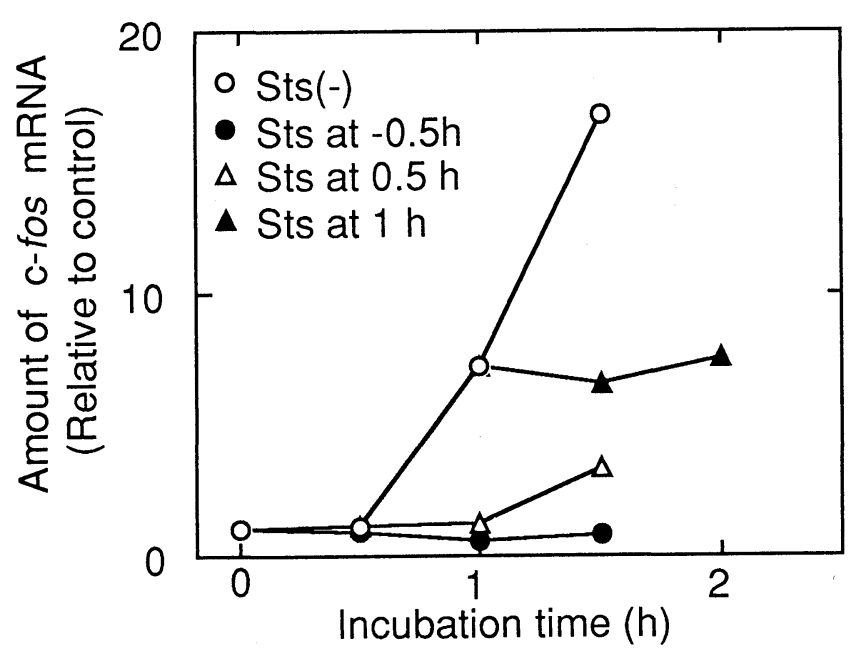

Fig. 6. Effect of staurosporine on calphostin-C induction of c-fos gene expression.

A549 cells were treated with calphostin-C (Cal-C) and staurosporine (Sts) under light. At the indicated times, RNAs were extracted and Northern blot analysis using c-fos cDNA probe was carried out as described in Fig. 2.

$O$, calphostin- $\mathrm{C}$ added at $0 \mathrm{~min} ; \bullet$, staurosporine added at $-30 \mathrm{~min}$ and then calphostin- $\mathrm{C}$ added at $0 \mathrm{~min} ; \triangle$, calphostin- $\mathrm{C}$ added at 0 min and then staurosporine added at $30 \mathrm{~min} ; \boldsymbol{\Lambda}$, calphostin- $\mathrm{C}$ added at $0 \mathrm{~min}$ and then staurosporine added at $60 \mathrm{~min}$.

treated with calphostin-C (the decrease was approximately $10 \%$ of control and statistically insignificant). When cells were treated first with calphostin-C for 30 min and then with calphostin-C and staurosporine for another $30 \mathrm{~min}$, cytosolic PKC activity decreased to a level similar to that in staurosporine-treated cells. TPA also reduced cytosolic PKC activity because of its binding to the $\mathrm{PKC}$ regulatory domain and subsequent translocation to the plasma membrane. When cells were first treated with calphostin- $\mathrm{C}$ and then with calphostin-C and TPA, PKC activity decreased to a level similar to that in the TPA-treated cells.

Next, the effect of staurosporine on calphostin-C /light induction of early-response gene expression was examined by Northern blot analysis. When staurosporine was added prior to calphostin-C, no c-fos mRNA accumulation was observed (Fig. 6). Staurosporine inhibited c-fos mRNA accumulation even after 1 h-treatment with calphostin-C, suggesting the involvement of $\mathrm{PKC}$ in calphostin-C/light induction of gene expression.

Thus, these results together suggest that unlike the case in vitro, PKC remains in the cytosolic fraction after calphostin-C/light treatment in vivo and this remaining cytosolic PKC apparently plays an important role(s) in the induction of early-response gene expression by calphostin-C.

\section{DISCUSSION}

We described novel light-dependent cellular responses to calphostin-C, which is known to inhibit PKC in vitro through interaction with diacylglycerol binding domain of PKC (16). In vitro studies demonstrate that the side chain of calphostin correlates with its PKC inhibition activity (16) and the perylenequinone ring confers photo-reactive oxidizing activity. Thus, calphostin$\mathrm{C}$ induces oxidative inactivation of $\mathrm{PKC}$ at the $\mathrm{Ca}^{+}$-induced hydrophobic site (10). Staurosporine was assumed to be less specific to PKC because of its binding to the catalytic domain of PKC (21). However, in our study, staurosporine specifically inhibited the PKC-mediated responses such as phosphorylation of the EGF receptor in response to TPA and phosphorylation of the $80 \mathrm{~K}$ protein (MARCKS) (8), a major cytosolic substrate for PKC $(14,20)$.

In contrast to staurosporine, calphostin- $\mathrm{C}$ in vivo does not seem to target cytosolic PKC. One possibility for the lack of PKC inhibition in vivo is that PKC may be altered in A549 cells so that it is insensitive to calphostin-C. Although lung carcinoma cell lines including A549 cells often express high levels of PKC activity in cytosol and A549 cells contain unique species of PKC (12), this is not likely because similar induction of earlyresponse gene expression was observed in another squamous carcinoma cell line NA (data not shown). More directly, calphostin-C/light in vitro inhibited PKC extracted from A549 cells only in the presence of $\mathrm{Ca}^{++}$as previously reported for rat brain-PKC and C6 glioma cells (10).

Another possibility is that cytosolic PKC is apparently more resistant to calphostin- $\mathrm{C}$ than membranebound PKC. Lipophilic calphostin-C readily accumulates in the membrane (24), and membrane-bound PKC is rapidly inactivated while cytosolic PKC is not (10). Further, the magnitude of cytosolic PKC inactivation seems different among cell lines and is dependent on a cytosolic scavenger mechanism which protects cytosolic PKC from radicals (10). Thus, it is likely that membrane-accumulated calphostin- $C$ generates active oxygen in a light-dependent reaction, enhances the EGF receptor phosphorylation, and subsequently activates the cytosolic PKC-dependent signal transduction pathway to early-response gene expression. This process for calphostin-C activation of signaling pathway is different from the pathway triggered by the EGF receptor tyrosine kinase and therefore apparently causes a unique kinetics of c-fos mRNA accumulation.

Our findings include several unique features for gene regulation by calphostin- $\mathrm{C}$, including light-dependent induction and possible involvement of PKC. To overcome the paradox that a protein kinase inhibitor induces phosphorylation and subsequent gene expression, 
we hypothesize that light-dependent oxidation on the plasma membrane is a triggering reaction of these unique cellular responses. Further elucidation of this hypothesis should provide insights not only in the regulation of early-response gene expression but also in the growth factor receptor phosphorylation mechanism.

Acknowledgments. The authors thank Mr. H. Okada and S. Imou for their technical assistance. The authors thank Dr. D. Bohmann at University of California, Berkeley, and Dr. M. Akiyama at the Radiation Effects Research Institute, Hiroshima, Japan for providing the probe and a cell line. The authors thank the Japanese Cancer Research Resources Bank for providing the probe. This work was supported by a grant-in-aid for Scientific Research from the Ministry of Education, Science and Culture, Japan.

\section{REFERENCES}

1. Aufray, C. and Rougeon, F. 1980. Purification of mouse immunoglobulin heavy-chain messenger RNAs from total myeloma tumor RNA. Eur. J. Biochem., 107: 303-314.

2. Behzadian, M.A. and Shimizu, N. 1985. Monoclonal antibody that immunoreacts with a subclass of human receptors for epidermal growth factor. Cell Struct. Funct., 10: 219-232.

3. Bohmann, D., Bos, T.J., Admon, A., Nishimura, T., Vogt, P.K., and TJiAN, R. 1987. Human proto-oncogene c-jun encodes a DNA binding protein with structural and functional properties of transcription factor AP-1. Science, 238: 13861392.

4. Bruns, R.F., Miller, F.D., Merriman, R.L., Howbert, J.J., Heath, W.F., Kobayashi, E., Takahashi, I., Tamaoki, T., and NAKANO, H. 1991. Inhibition of protein kinase $C$ by calphostin C is light-dependent. Biochem. Biophys. Res. Commun., 176: 288-293.

5. Feinberg, A.P. and Vogelstein, B. 1983. A technique for radiolabeling DNA restriction endonuclease fragments to high specific activity. Anal. Biochem., 132: 6-13.

6. Gamou, S., Hirai, M., Rikimaru, K., Еnоmoto, S., and Shimizu, N. 1988. Biosynthesis of the epidermal growth factor receptor in human squamous cell carcinoma lines: Secretion of the truncated receptor is not common to epidermal growth factor receptor-hyperproducing cells. Cell Struct. Funct., 13: $25-38$.

7. Gamou, S. and Shimizu, N. 1988. Glycosylation of the epidermal growth factor receptor and its relationship to membrane transport and ligand binding. J. Biochem. (Tokyo), 104: 388396.

8. Gamou, S. and Shimizu, N. 1994. Calphostin-C stimulates epidermal growth factor receptor phosphorylation and internalization via light-dependent mechanism. J. Cell. Physiol., 158: 151159.

9. Gamou, S., Shimosato, Y., and Shimizu, N. 1990. Regulation of the epidermal growth factor receptor gene expression in a morphological variant isolated from an epidermal growth factor receptor-deficient small cell lung carcinoma cell line. Cell Growth Differ, 1: 351-359.
10. Gopalakrishna, R., Chen, Z.H., and Gundimeda, U. 1992. Irreversible oxidative inactivation of protein kinase $C$ by photosensitive inhibitor calphostin C. FEBS Lett., 314: 149-154.

11. Greenberg, M.E. and ZifF, E.B. 1984. Stimulation of 3T3 cells induces transcription of the c-fos proto-oncogene. Nature, 311: 433-438.

12. Hirai, M., Gamou, S., Kobayashi, M., and Shimizu, N. 1989. Lung cancer cells often express high levels of protein kinase C activity. Jpn. J. Cancer Res. (Gann), 80: 204-208.

13. Hirai, M., Kobayashi, M., and Shimizu, N. 1990. Reduced tyrosine phosphorylation and nonresponsiveness to EGF-mediated cytotoxicity in EGF receptor-hyperproducing UCVA-1 cells. Cell Signal., 2: 245-252.

14. Hirai, M. and Shimizu, N. 1989. Stimulation of a MR 80,000 protein phosphorylation by EGF in EGF receptor-hyperproducing human tumor cells. J. Cell Physiol., 139: 9-17.

15. KerR, L.D., Holt, J.T., and Matrisian, L.M. 1988. Growth factors regulate transin gene expression by c-fos-dependent and c-fos-independent pathways. Science, 242: 1424-1427.

16. Kobayashi, E., Nakano, H., Morimoto, M., and Tamaoki, T. 1989. Calphostin C (UCN-1028C), a novel microbial compound, is a highly potent and specific inhibitor of protein kinase C. Biochem. Biophys. Res. Commun., 159: 548-553.

17. Lee, W., Mitchell, P., and Tijan, R. 1987. Purified transcription factor AP-1 interacts with TPA-inducible enhancer elements. Cell, 49: 741-752.

18. Mcdonnell, S.E., KerR, L.D., and Matrisian, L.M. 1990. Epidermal growth factor stimulation of stromelysin mRNA in rat fibroblasts requires induction of proto-oncogenes c-fos and c-jun and activation of protein kinase C. Mol. Cell Biol., 10: 4284-4293.

19. Muller, R., Bravo, R., Burckhardt, J., and Curran, T. 1984. Induction of c-fos gene and protein by growth factors precedes activation of c-myc. Nature, 312: 716-720.

20. SaKai, K, Hirai, M., Kudoh, J., Minoshima, S., and Shimizu, N. 1992. Molecular cloning and chromosomal mapping of a cDNA encoding human $80 \mathrm{~K}-\mathrm{L}$ protein: Major substrate for protein kinase C. Genomics, 14: 175-178.

21. TAMAOKI, T. 1991. Use and specificity of staurosporine, UCN01, and calphostin C as protein kinase inhibitors. Methods Enzymol., 201: 340-347.

22. Van Straaten, F., Muller, R., Curran, T., Van Beveren, C., and Verma, I.M. 1983. Complete nucleotide sequence of a human c-onc gene: Deduced amino acid sequence of the human c-fos protein. Proc. Natl. Acad. Sci. USA, 80: 3183-3187.

23. Waht, M.I., Jones, G.A., Nishibe, S., Rhee, S.G., and CARPENTER, G. 1992. Growth factor stimulation of phospholipase C-gammal activity. Comparative properties of control and activated enzymes. J. Biol. Chem., 267: 10447-10456.

24. Wang, S.S.-H., Mathes, C., and Thompson, S.H. 1993. Membrane toxicity of the protein kinase $C$ inhibitor calphostin A by a free-radical mechanism. Neurosci. Lett., 156: 145-148.

(Received for publication, March 28, 1994

and in revised form, April 26, 1994) 